Revista do Programa de Pós-Graduação em Educação da Unochapecó

ISSN 1984-1566 (on-line) ISSN 1415-8175 (impressa)

\title{
AS NARRATIVAS SOBRE SER CRIANÇA: do desencanto ao encantamento em trajetória de acadêmico a pesquisador
}

\author{
LAS NARRATIVAS SOBRE SER NIÑO: del desencanto al \\ encantamiento en la trayectoria de alumno a pesquisador
}

\begin{abstract}
NARRATIVES ABOUT BEING A CHILD: from an uninspired to an inspired researcher
\end{abstract}

Antonio Morais da Costa

http://orcid.org/0000-0003-0251-0509

Andrea Abreu Astigarraga ${ }^{2}$

http://orcid.org/0000-0001-9614-1999

\begin{abstract}
Resumo
O principal objetivo deste artigo é descrever e analisar o processo formativo de um pesquisador iniciante diante das narrativas das crianças da turma do infantil IV sobre ser criança. O lócus da pesquisa foi um Centro de Educação Infantil em um município da região norte do estado do Ceará. A abordagem teórico-metodológica qualitativa de ouvir as crianças está em consonância com os estudos realizados por pesquisadores, tais como Sarmento (2008); Cohn (2005); Costa e Astigarraga (2020), Passeggi (2014); entre outros. O procedimento metodológico principal foi utilização de um boneco representando um extraterrestre que visita a escola, inspirado em LaniBayle (2018); Conti e Passeggi (2014) e Furlanetto (2014), rodas de conversas coletivas, com pequenos grupos de crianças, gravadas e transcritas. Foi possível refletir sobre a infância vivida por elas, deixando evidente a necessidade de uma escuta sensível acerca do processo formativo tanto do pesquisador-iniciante quanto das crianças para que existam possibilidades de transformação, ou seja, de pesquisador desencantado para uma postura de pesquisador encantado.
\end{abstract}

Palavras-chave: Crianças. Educação Infantil. Processo Formativo. Narrativas (Auto) biográficas.

\section{Resumen}

El principal objetivo de este artículo es describir y analizar el proceso educativo de un pesquisador principiante delante de las narrativas de los alumnos del curso infantil IV sobre ser niño. El lugar de

1 Graduado em Pedagogia. Universidade Estadual Vale do Acaraú - UVA. Membro do Grupo de Estudos e Pesquisas (Auto)biográficas - GEPAS -E-mail: moraisfruticultura@gmail.com

2 Pós-Doutora em Educação. Universidade Estadual Vale do Acaraú - UVA. Coordenadora do Grupo de Estudos e Pesquisas (Auto)biográficas - GEPAS - E-mail: andrea_astigarraga@uvanet.br

Como referenciar este artigo:

COSTA, A. M. DA.; ASTIGARRAGA, A. A. As narrativas sobre ser criança: do desencanto ao encantamento em trajetória de acadêmico a pesquisador. Revista Pedagógica, v. 23, p. 1-21, 2021. 
la pesquisa fue un Centro de Educación Infantil en un municipio de la región norte del estado del Ceará. El abordaje teórico-metodológico cualitativo de oír a los niños está en consonancia con los estudios realizados por pesquisadores, tales como, Sarmento (2008); Cohn (2005); Costa e Astigarraga (2020), Passeggi (2014); entre otros. El proceso metodológico principal fue la utilización de un muñeco representando un extraterrestre que visita la escuela, inspirado en Lani-Bayle (2018); Conti e Passeggi (2014) e Furlanetto (2014), ruedas de conversación colectiva, con pequeños grupos de niños, grabadas y transcritas. Fue posible reflexionar sobre la infancia vivida por ellos, dejando evidente la necesidad de una escucha sensible acerca del proceso educativo tanto del investigador principiante como de los infantes, para que existan posibilidades de transformación, o sea, de pesquisador desencantado para una postura de pesquisador encantado.

Palabras-clave: Niños. Educación Infantil. Proceso Educativo. Narrativas Autobiográficas.

\begin{abstract}
The aim of this article is to describe and analyze the formative process of early researchers after listening to the narratives of kindergarten children about their childhood. The research was conducted at a Child Education Center in a municipality in the northern region of the state of Ceará. The qualitative theoretical-methodological approach of listening to children is in agreement with studies carried out by researchers such as Sarmento (2008), Cohn (2005), Costa and Astigarraga (2020), Passeggi (2014), among others. The main methodological procedure was to use an extraterrestrial puppet to interact with the children, inspired by Lani-Bayle (2018), Conti and Passeggi (2014) and Furlanetto (2014), and collective conversations with small groups of children, which were recorded and transcribed. By reflecting on their childhood, we realized the need for sensitive listening about the formative process of children and early researchers to foster transformations, that is, enabled me to change from an uninspired researcher to an inspired researcher.
\end{abstract}

Keywords: Children. Child education. Formative Process. Autobiographical narratives

\title{
INTRODUÇÃO
}

Neste texto, vou expor a minha experiência oriunda da pesquisa de iniciação científica da Fundação Cearense de Apoio ao Desenvolvimento Científico e Tecnológico FUNCAP: Narrativas autobiográficas das crianças, professores e agentes educativos em espaços escolares e não escolares sobre ser crianças, viver a infância, escola e processo ensino - aprendizagem³.

3 A presente pesquisa teve aprovação pelo Comitê de Ética, com o CAEE: 69329717.3.0000.5053, obedecendo aos requisitos propostos na Resolução 580/2016 do Conselho Nacional de Saúde, a qual advoga que a pesquisa feita com humanos respeitará todos os aspectos éticos dos sujeitos, garantindo sua integridade e seu livre arbítrio para com a participação da pesquisa. 
Meu contato 4 com a pesquisa iniciou no $2^{\circ}$ período do Curso de Pedagogia da Universidade Estadual Vale do Acaraú (UVA) Sobral - CE, em 2017, a partir da disciplina História Social da Infância. Nesta disciplina, conheci autores/as que pesquisavam e estudavam a infância e a criança como protagonista, detentora de fala, de escuta e de direitos. Logo, me interessei pela temática. Após minha aproximação com a professora, fui convidado por ela para ser bolsista de iniciação científica e também integrante do Grupo de Estudos e Pesquisas (Auto)biográfica (GEPAS). A partir deste fato, iniciou a minha formação acadêmica sobre a temática da infância.

Durante a minha entrada no campo, na escola que foi realizada a coleta de dados desta pesquisa, na maioria das vezes, cheguei a desacreditar na autoridade das falas das crianças, dos significados e das reflexões que suas narrativas traziam. Esse momento aconteceu quando a professora orientadora perguntou sobre o que eu estava notando da pesquisa. Lembro-me que a respondi: "Professora, as crianças não estão sabendo falar e articular suas ideias para aquilo que nós estamos pesquisando. Eu acho que a outra etapa da pesquisa com as crianças do ensino fundamental será mais proveitosa, pelo fato de terem uma melhor compreensão”. A professora, então, ficou calada. E eu, naquele momento, fiquei sem entender o silenciamento dela.

Com o passar dos dias, fui engajando-me mais ainda na pesquisa com as crianças. Fui criando um vínculo afetivo e de aproximação com elas. E mais do que isso, durante a leitura de suas narrativas pude notar a relevância de suas falas e da minha atuação de pesquisador com elas. Essa tomada de consciência de uma postura crítica e reflexiva levanos a entender que: "o desenvolvimento humano ocorre em meio à atividade prática mediadora da relação ativa indivíduo-meio. A tarefa da educação consiste em dirigir e em tornar produtivo, do ponto de vista pedagógico, esse processo de relação ativa" (KLINGBERG, 1997, p. 86 apud LIBÂNEO, 2011, p. 128).

De modo que, o pesquisador entenda que a pesquisa é um processo teórico e prático, portanto, se faz necessário apropriar-se dos estudos teóricos e tê-los consigo no instante em que se realiza a pesquisa de campo com atores sociais. Dessa forma, o 
entrelaçamento dos estudos teóricos simultaneamente com a coleta dos dados e da interpretação das narrativas das crianças ajudou-me a compreender que as crianças sabem falar, articular ideias e, principalmente, são detentoras de um vasto conhecimento, tendo, assim, capacidade cognitiva suficiente para elaborar suas narrativas de vida.

Para Libâneo (2011, p. 129): “É nesse processo da atividade humana prática que os indivíduos vão criando, produzindo e transformando objetos, instrumentos de trabalho, conhecimentos, modos de ação, técnicas, linguagem, valores, sentimentos etc., constituindo o mundo humano". Foi perceptível o meu amadurecimento como pesquisador durante todo esse momento em que realizei a pesquisa com as crianças. Passei a sentir-me de pesquisador desencantado a pesquisador encantado e dedicado aos estudos que tematizam a participação das crianças no campo científico - educacional.

O espaço - tempo das crianças está predominantemente marcado pelas vivências formais de educação. Elas passam tempo considerável dentro da escola e da sala de aula. Nesse sentido, pergunto: qual a importância de se pesquisar crianças na formação inicial do pedagogo? Como a turma do infantil IV dá significado às suas narrativas sobre ser criança? Em que medida a escola possibilita a vivência de ser criança imbricada na experiência de brincar, ou melhor, aprender brincando, na turma do Infantil IV? As crianças usufruem do direito (constitucional) de brincar e aprender brincando na Educação Infantil? Será que a ludicidade proporciona imaginação entre as crianças ou o saber-conteúdo prevalece?

Portanto, o principal objetivo deste artigo é descrever o processo formativo de um pesquisador iniciante diante das narrativas das crianças da turma do infantil IV sobre ser criança. O lócus da pesquisa foi um Centro de Educação Infantil, em um município da região norte do estado do Ceará.

Reconhecemos as crianças como atores sociais, sujeitos de direitos. Sendo assim, a abordagem teórico-metodológica qualitativa de ouvir as crianças sobre o que pensam sobre ser criança está em consonância com os estudos realizados por pesquisadores/as da Sociologia da Infância que utilizaremos como aportes teóricos-metodológicos, tais como, Sarmento (2008); Cohn (2005); Costa e Astigarraga (2020), Passeggi (2014); entre outros. Esta pesquisa considera as perspectivas das crianças a partir de suas vozes. Seguimos procedimentos do Comitê de Ética obtendo a anuência das crianças, dos pais e professoras. 
A metodologia da pesquisa é a narrativa (auto)biográfica com crianças possibilitando que atribuam significados às suas vivências de ser criança no espaço escolar. Os procedimentos metodológicos foram inspirados nas investigações de Lani-Bayle (2018); Conti e Passeggi (2014) e Furlanetto (2014) na utilização de um boneco representando um extraterrestre que visita a escola, rodas de conversas coletivas com pequenos grupos de crianças, gravadas e transcritas.

Este texto está organizado em quatro seções. A primeira trata dos marcos legais da Educação Infantil e o enfoque no aprender brincando. A segunda destaca a escola como espaço de escuta das crianças. A terceira, a narrativa (auto)biográfica como dispositivo de investigação na pesquisa com crianças. Na última seção apresentamos o resultado da pesquisa com as narrativas sobre ser criança da turma do Infantil IV na qual interpretamos e analisamos os dados coletados.

\section{OS MARCOS LEGAIS DA EDUCAÇÃO INFANTIL E O ENFOQUE NO APRENDER BRINCANDO}

O que devemos esperar da Educação Infantil no Brasil à luz dos marcos legais? Em 1996, a Lei de Diretrizes e Bases da Educação Nacional - LDBEN, em seu Art. 29, estabelece que a Educação Infantil deve garantir o desenvolvimento integral da criança, em diversos aspectos: físico, psicológico, intelectual, social, complementando a ação da família e comunidade (BRASIL, 1996).

No ano de 1988 foi elaborado o Referencial Curricular Nacional para a Educação Infantil - RCNEI, um documento orientativo, não normativo e nem obrigatório, mas que abrange reflexões educacionais, objetivos, conteúdos e orientações didáticas para a Educação Infantil. Em relação ao brincar, o RCNEI (1998) destaca que as crianças devem ter o direito de brincar durante as práticas pedagógicas em sala de aula. O brincar representa uma: “[...] forma particular de expressão, pensamento, interação e comunicação infantil” (BRASIL, 1998, p. 13).

A Resolução $n^{\circ}$ 5, de 17 de dezembro de 2009 fixa as Diretrizes Curriculares Nacionais para a Educação Infantil - DCNEI (2009), documento imprescindível para a 
Educação Infantil pelo fato de prever a organização dessa modalidade educativa, reforçando em seu artigo $4^{\circ}$, que:

\begin{abstract}
As propostas pedagógicas da Educação Infantil deverão considerar que a criança, centro do planejamento curricular, é sujeito histórico e de direitos que, nas interações, relações e práticas cotidianas que vivencia, constrói sua identidade pessoal e coletiva, brinca, imagina, fantasia, deseja, aprende, observa, experimenta, narra, questiona e constrói sentidos sobre a natureza e a sociedade, produzindo cultura (BRASIL, 2009, p. 01).
\end{abstract}

A orientação acima apresenta a criança como centro do planejamento curricular, que está em constante desenvolvimento e, por isso, justifica que o brincar tem que estar ligado às propostas pedagógicas na Educação Infantil.

Destacamos também a Base Nacional Comum Curricular - BNCC (2018), documento normativo para a elaboração dos currículos escolares e propostas pedagógicas para a educação nacional. Esse documento retrata inovações para a educação brasileira, estruturando-se de modo a esclarecer competências e habilidades do estudante, que devem ser desenvolvidas a partir da Educação Infantil, perpassando pelo Ensino Fundamental e atingido também o Ensino Médio. A BNCC (2018) enfatiza que a brincadeira na Educação Infantil promove a interação que:

[...] durante o brincar caracteriza o cotidiano da infância, trazendo consigo muitas aprendizagens e potenciais para o desenvolvimento integral das crianças. Ao observar as interações e a brincadeira entre as crianças e delas com os adultos, é possível identificar, por exemplo, a expressão dos afetos, a mediação das frustrações, a resolução de conflitos e a regulação das emoções (BRASIL, 2018, p. 37).

De acordo com o que foi mencionado acima, o brincar na Educação Infantil é de suma importância para o desenvolvimento integral das crianças. O brincar proporciona a socialização, a interação e estimula o raciocínio das crianças que contribui para o amadurecimento cognitivo, pessoal e social delas. Ao brincar, podem expressar-se umas com as outras, aprender regras compartilhadas, e acima de tudo, criar respeito pelas demais crianças no instante em que brincam.

Além de ser um instrumento de observação que o professor pode utilizar para notar o desenvolvimento de habilidades que são pertinentes às crianças durante a infância. Portanto, o brincar: “[...] faz parte da natureza das crianças [...]. Infância e ludicidade constituem um binômio umbilicalmente ligado num compromisso de importância seminal 
para a formação da criança" (SILVA, 2017, p. 27). Nesse sentido, a brincadeira em si tem uma intencionalidade pedagógica. As crianças são incentivadas a pensar, a participar e a trabalharem em grupo, elevando sua capacidade cognitiva, psicomotora e social, que ampliam a linguagem e a ação representativa das crianças.

No entanto, cabe a pergunta: qual o tempo de brincar na sala da turma do Infantil IV? As escolas primam pela garantia da criança aprender brincando na Educação Infantil? Em que patamar a brincadeira está no espaço escolar organizado pelos adultos para as crianças? Silva (2017) nos ajuda a refletir sobre este fato:

Por detrás da institucionalização desenfreada das crianças e das demais capturas de suas vidas por outras obrigações ditadas pelos adultos, minguou-se o tempo só delas e para elas [...] Tempos desafiantes estes para quem tem em mãos a responsabilidade de ajudar as crianças a construir uma agenda quotidiana suficientemente flexível para que nela caiba espaço e tempo que inverta a pirâmide que hoje coloca a brincadeira no seu patamar mais periclitante. (SILVA, 2017, p. 37).

Com essa angústia pedagógica, fomos à turma do Infantil IV perguntar às crianças: por que é bom ser criança? Escutamos suas narrativas e na última seção deste texto, refletiremos sobre elas.

\section{A ESCOLA COMO ESPAÇO DE ESCUTA DAS CRIANÇAS}

A escola, muitas vezes, demonstra ser um ambiente não muito democrático, atingindo principalmente as crianças, que ficam à margem de um sistema educativo que não as ouve, impossibilitando que haja uma reflexão do processo de ensino-aprendizagem e da prática docente por parte delas. Isso acontece porque no contexto municipal onde foi feita a pesquisa, as escolas têm como principal objetivo obter resultados por meio das crianças em testes e em avaliações, tendo como meta principal o rendimento escolar dos alunos para atingir e manter o Índice de Desenvolvimento da Educação Básica - IDEB.

Como solução a essa formação conservadora e tecnicista das crianças na Educação Infantil, apostamos que as práticas pedagógicas do professor podem ser melhor desenvolvidas e ampliadas quando se faz das crianças sujeitos participantes do ato educativo, ouvindo-as, notando as sugestões e as contribuições que elas podem oferecer 


\section{REVISTA}

Revista do Programa de Pós-Graduação em Educação da Unochapecó ISSN 1984-1566 (on-line) ISSN 1415-8175 (impressa)

ao processo de aprendizagem. Esses fatores redirecionam o professor a trabalhar na perspectiva das crianças fazendo delas seres reflexivos e mediadores do ato pedagógico.

Entendemos, de acordo com Rosado e Campelo (2010, p. 239):

[...] que as crianças possuem e constroem saberes, têm visão de mundo que, se explicitadas e mediadas, podem tornar-se elementos importantes da investigação científica. Nesse sentido, discutir os saberes infantis sobre a escola assume relevância, principalmente na perspectiva teórico-prática, ou seja, se as formulações teóricas se aplicarem à prática [...], possivelmente tornarão os alunos partícipes efetivos do processo.

Tento em vista a capacidade reflexiva e cognitiva das crianças, que denota saberes expressos sobre o mundo, oportunizá-las ao diálogo e à escuta dentro do espaço escolar, poderá contribuir satisfatoriamente no redirecionamento das práticas docentes, além de tornar a escola um espaço democrático, que dá voz e vez aos seus atores sociais, no caso, as crianças. Tratando-se sobre as vozes das crianças no espaço escolar, Brostolin e Azevedo (2021, p. 11), afirmam que:

Desenvolver a escuta infantil é uma proposta que deve estar presente em várias instâncias da sociedade, no entanto, ela se torna necessária no contexto educativo, uma vez que os espaços institucionais, especialmente os da Educação Infantil, são muitas vezes, onde as crianças passam a maior parte de seus dias; portanto, devem ser abertos ao diálogo e à participação efetiva das crianças, em seus cotidianos e em suas rotinas.

Levando-se em conta os aspectos observados, é de suma importância que se agreguem nas escolas, iniciativas com o objetivo de criar um ideário participativo para com as crianças, fazendo com que elas se sintam parte da escola e que se vejam como sujeitos valorizados, que podem contribuir para o desenvolvimento de si e também para o sucesso da escola.

\section{A NARRATIVA (AUTO)BIOGRÁFICA COMO DISPOSITIVO DE INVESTIGAÇÃO NA PESQUISA COM CRIANÇAS}

Segundo Rocha e Passeggi (2018, p. 59): "Pela narrativa a criança tem a possibilidade de compartilhar suas experiências e evidenciar para o pesquisador aspectos da constituição de sua subjetividade, que se constitui no ato de narrar". O ato de narrar 
ajuda a criança a organizar suas vivências e a refletir sobre elas, podendo elencar para o pesquisador, os fatos marcantes de suas experiências já vividas, dando significados e atribuindo valores de importância sobre elas.

Portanto, a pesquisa com as crianças deve ser realizada em torno delas, já que são elas que vivem e experimentam com o meio, as marcas vivenciais de suas infâncias. Desta forma, as crianças são formadoras de suas histórias de vidas, que podem ser acessadas no diálogo com elas, que formam e estruturam suas próprias narrativas de vida.

A criança passa, então, a ser sujeito de sua história de vida quando narra, a protagonista que anuncia seu enredo. A narrativa (auto)biográfica, portanto, é um dispositivo de investigação imprescindível na pesquisa com crianças, de maneira peculiar, a criança se sente valorizada e conduzida a refletir sobre si, debruçando-se sobre sua própria história. Nesse sentido:

\footnotetext{
A história de vida acontece na narrativa. O que dá forma ao vivido e à experiência dos homens são as narrativas que eles fazem de si. Portanto, a narrativa não é apenas o instrumento de formação, a linguagem na qual esta se expressaria: a narração é o lugar no qual o indivíduo toma forma, no qual ele elabora e experimenta a história de sua vida (DELORY - MOMBERGUER, 2008, p. 160).
}

Mais do que narrar, a criança experimenta e valida suas experiências já vividas no instante em que fala, pois, sua história de vida está na base da constituição da criança enquanto sujeito da ação e da reflexão humana. Desse modo, a criança, ao ingressar pelo mundo da narrativa (auto)biográfica, está narrando de fato aquilo que para ela tem significado.

Para se ter acesso ao modo como as crianças vivem e concebem as suas infâncias, os pesquisadores precisam estabelecer um diálogo com elas, considerando-as autores de suas próprias vidas. No método narrativo, as crianças exploram, representam e trazem significados do seu vivido e dos espaços as quais estão inseridas, como a escola.

Nas narrativas: "O saber da experiência se dá na relação entre o conhecimento e a vida humana" (LARROSA, 2002, p. 26). Refletindo sobre isso, frisamos que as experiências que as crianças têm de suas vivências são narradas pelo fato dessas experiências propiciarem conhecimento e aprendizagem diversificados que se cruzam dentro da formação humana de cada uma. 
Nesse caso, Larrosa (2002) enfatiza que o saber da experiência é entendido como uma aprendizagem daquilo que nos acontece. Esse saber pode ser notado no modo como alguém vai respondendo ao que vai lhe acontecendo ao longo da vida e no modo como vamos dando sentindo ao acontecer do que nos acontece. Nesse contexto, ratificamos que as crianças são ativas de sua própria experiência, por serem capazes de refletir suas próprias vivências e, assim, enunciar a aprendizagem que têm de seus momentos vividos. Isso pode ser notado no momento em que se investe na capacidade da criança de narrar como ser aprendiz de sua vida.

Essa aprendizagem que as crianças têm sobre a vida pode ser explicada a partir das narrativas de experiências, nas quais:

\footnotetext{
Os sujeitos se fazem autores e assinam as compreensões que produzem sobre as suas vidas. Apor sua assinatura decorre da não existência de álibi no mundo para um sujeito evadir-se de sua responsabilidade histórica. Cada sujeito, como ser único, vive e experimenta situações reais que o implicam no ato vivido, na experiência ocorrida. Nessa unicidade é que ocorrem o ato e o dever concreto de dizer (responder), de responsabilizar-se pelo que se diz (LIMA; GERALDI; GERALDI, 2015, p. 30).
}

Nesse contexto, em suas narrativas, as crianças tendem a falar de suas experiências, porque emergem como protagonistas desde a tenra infância, apropriando-se de si, entrando em seu eu interior para refletir, investigar e se apoderar de seus marcos vivenciados, para, dessa forma, darem sentido ao vivido durante os ciclos da infância, adquirindo uma compreensão global de sua formação humana, passando pelo desenvolvimento físico, cognitivo, social e afetivo. Dessa forma, nas narrativas, as crianças adquirem e enunciam conhecimento de suas vivências porque perpassam por seus aspectos sociais, culturais, familiares e educacionais.

Para Rocha e Passeggi (2018, p. 57), as crianças: "têm todas as condições de se autobiografar, de refletir sobre elas mesmas e de ser agentes socialmente ativos no seu cotidiano e nas histórias de sua vida”. Em concordância com as autoras, entendemos que as crianças possuem capacidade cognitiva suficiente para o exercício de elaborar narrativas de si, de modo, que desenvolvem desde sua tenra infância, as potencialidades de tomar para si, no instante em que narram os reflexos de sua representação no mundo, que estão relacionados aos acontecimentos e às situações ocorridas em suas infâncias. 
O ato de autobiografar, como destaca Rocha e Passeggi (2018), tem importantes consequências para compreender como a criança reconfigura, em suas narrativas, as experiências de escolarização e como vão construindo a própria subjetividade. Como visto, na narrativa, as crianças acessam o código de sua subjetividade humana, que é responsável por fornecê-las o conhecimento e os saberes de suas vivências, que de certo modo configura os princípios norteadores da atividade de biografização. De tal modo, a narrativa como produtora de subjetividade, garante à criança o saber experiencial de sua história de vida e a lança como arguidora de sua palavra, que a legitima em seu discurso, demonstrando por meio de sua narrativa o conteúdo subjetivo existente e estruturador de sua consciência potencializadora e reveladora de sua linguagem.

Desta forma, ao mesmo tempo em que a narrativa estrutura a subjetividade da criança, também estimula a prática da linguagem, que é imprescindível no que diz respeito ao progresso e desenvolvimento da criança, pois é a partir da linguagem que as crianças mantêm relação com o outro, na medida em que este mecanismo colabora também para que a criança descubra, explore e desenvolva seus próprios instrumentos comunicativos e sociais. A linguagem, também, propicia que as crianças se compreendam e se situam no espaço e tempo atual. Vygotsky (1984 apud SOUZA, 2000, p. 17) nos ajuda a entender melhor a função da linguagem na criança, ao afirmar que:

O uso da linguagem se constitui na condição mais importante do desenvolvimento das estruturas psicológicas superiores (a consciência) da criança. O conteúdo da experiência histórica do homem, embora esteja consolidado nas criações materiais, encontra-se também generalizado e refletese nas formas verbais de comunicação entre os homens sobre estes conteúdos. A interiorização dos conteúdos historicamente determinados e culturalmente organizados se dá, portanto, principalmente por meio de linguagem, possibilitando, assim, que a natureza social das pessoas torne-se igualmente sua natureza psicológica.

Nesse sentido, a consciência das crianças pode ser compreendida como um repositório de arquivos de suas vivências, que ao serem instigadas pelo uso da linguagem, o acessam, o refletem, o retratam, ou seja, organizam de modo perspicaz os conhecimentos que têm de suas vivências. Assim, o conhecimento social que as crianças têm se transformam em conhecimento psicológico no momento em que está narrando. As crianças, em sua própria linguagem, transmitem e anunciam todo o conhecimento que têm 
da realidade em que vivem, ou seja, a interação verbal que as crianças utilizam no momento de suas narrativas alicerçam a realidade cotidiana de suas vidas, já que:

\begin{abstract}
O discurso verbal é diretamente ligado à vida em si e não pode ser divorciado dela sem perder sua significação. Qualquer enunciado envolve uma série de critérios (éticos, políticos, cognitivos, afetivos) que levam em consideração muito mais do que está incluído nos fatores estritamente verbais do enunciado. São os julgamentos de valor e as avaliações que fazem com que o discurso verbal se envolva diretamente com a vida, formando com ela uma unidade indissolúvel. A língua em si, tomada isoladamente, não pode, naturalmente, ser verdadeira ou falsa, ousada ou tímida. Cada ato de fala não é só o produto do que é dado, sempre cria algo que nunca existiu antes, algo absolutamente novo e não repetitivo que se revela na entoação (SOUZA, 2000, p. 14).
\end{abstract}

Dessa forma, na elaboração das narrativas das crianças, elas, em suas falas, fazem uma ligação com a própria vida. E isso é perceptível quando notamos as formas como as crianças vão dando sentido aos seus momentos e às suas experiências, que sempre estão voltadas ao percurso de suas vidas.

Por isso, durante a pesquisa com as crianças, é fundamental que o pesquisador privilegie todas as formas de expressão da criança, pois estas expressões condizem com a linguagem que a criança possui, representa e compreende algo. Nesse caso, a entrevista com as crianças se torna um momento de construção de sua subjetividade e também da apropriação da linguagem para a produção de suas narrativas, e os conteúdos das vivências das crianças, sejam eles de marcos históricos, culturais ou sociais, tornam-se acessíveis porque postulam conhecimento e ação de comunicação no método narrativo junto ao pesquisador.

\title{
4 NARRATIVAS SOBRE SER CRIANÇA DA TURMA DO INFANTIL IV
}

A presente pesquisa teve aprovação pelo Comitê de Ética da UVA, na qual tivemos a anuência das crianças, das professoras e dos pais das crianças, que assinaram o Termo de Consentimento Livre e Esclarecido - TCLE, tendo sido planejada com o grupo gestor e com as professoras da escola.

Primeiramente, antes de fazermos a coleta de dados, realizamos o período de observação, de inserção ao lócus da pesquisa. Período em que fomos conhecendo a escola, 
o espaço da pesquisa em si, nos aproximando das professoras e das crianças para criar laços de confiança. Segundo Martins Filho (2011, p. 94), o momento de observação é importante porque: "somente assim, [...], poderá gerar um envolvimento muito maior com os sujeitos pesquisados, pois o contato direto permite construir uma atmosfera muito positiva, lúdica e humana no desenvolvimento da pesquisa com as crianças".

Dessa forma, durante a pesquisa com as crianças, o envolvimento do pesquisador para com elas é um fator imprescindível para obter-se êxito na recolha dos dados. Ao perceber que o pesquisador está aberto à aproximação e ao diálogo, as crianças, notadamente, se sentirão acolhidas e prontas para revelar aquilo que nós, pesquisadores, temos interesse em investigar a partir de sua participação.

É preciso envidar esforços, explicitando os limites e descobrindo as possibilidades para estabelecer uma comunicação fértil com as crianças pequenas, principalmente no intuito de inventar, criar e estabelecer outras formas de comunicação com elas, o que coincidirá com a criação de outros procedimentos teórico-metodológicos de pesquisa (MARTINS FILHO, 2011, p. 95).

Logo, cabe ao pesquisador o dever de pensar em estratégias que o faça se aproximar das crianças, já que para se aprofundar em suas particularidades, as crianças necessitam ser ouvidas e interpretadas. Seja em assuntos inerentes à pesquisa ou não. $O$ que importa, nesse momento, é o vínculo que será criado com elas, que, posteriormente, corresponderá com o foco e com o que se pretende pesquisar junto delas.

Iniciamos a coleta de dados entre os meses de novembro e dezembro de 2019 nas terças e quintas-feiras, das $13 \mathrm{~h} 30$ min às $16 \mathrm{~h} 30$ min com três turmas do Infantil IV (crianças na faixa etária de 4 a 5 anos de idade). A equipe de pesquisa sempre foi bem recebida pelo corpo gestor e docente da escola, e a coordenadora pedagógica acompanhou em algumas atividades. A coordenadora e a diretora da escola colocaram como condição da realização da pesquisa que nenhuma criança ficasse de fora. Portanto, todas as crianças das turmas participaram da pesquisa. Para organizar as rodas de conversa, fizemos 3 grupos com 15 crianças cada. O tempo destinado aos encontros era de 01 (uma) hora. Abaixo, destacamos os procedimentos realizados para a coleta de dados, através do protocolo do alienígena, citado no item anterior.

a) Abertura: o pesquisador apresentou às crianças o pequeno Alienígena que vem de um planeta onde não tem escola e deseja que as crianças contém tudo o que sabem 
sobre ela. Pesquisador: - "Gente, vocês gostam de amiguinhos novos? Se eu trouxesse um amiguinho novo, para conversar com a gente, vocês o receberiam aqui? Ele está escondidinho aqui, eu posso trazê-lo para cá? Olha aqui onde ele está! Ele veio lá do planeta dele, longe, longe, viajou, viajou até chegar aqui para conhecer vocês! E ele veio perguntar para vocês; o que é escola?"

b) Diálogo: as crianças falam espontaneamente sobre a escola e o pesquisador privilegiou duas perguntas: o que tem de bom na escola e o que tem de bom em ser criança? Nas 3 rodas de conversas foram feitas entrevistas narrativas com as crianças, gravadas em vídeo, transcritas e submetidas à análise.

c) Despedida: A criança se despede do E.T - Alien que deve voltar ao seu planeta. Cada criança fez um desenho da sua escola para o E.T. levar de lembrança. No final da roda de conversa, cada criança deu um abraço no boneco.

Para elaboração deste artigo, selecionamos as narrativas sobre ser criança, da turma do Infantil IV. Elas disseram que é bom ser criança porque podem "Brincar aqui na escola, no parquinho!” (Menino 01). "Porque tem brincadeiras no parquinho! Porque eu gosto de brincar de pega-pega!” (Menino 02). “Porque pode brincar com os amiguinhos!” (Menino 05).

Essas narrativas das crianças representam os momentos de brincadeiras e de vivências que compartilham umas com as outras quando se divertem. Dessa forma, a narrativa é tida como um método que desperta, reproduz e amplia as experiências que as crianças têm de sua cultura infantil. No momento de narração, as crianças são conduzidas a pensar e a refletir sobre as marcas de suas vivências. A narrativa, portanto, viabiliza, circunscreve e dá significado à vida das crianças no momento em que elas narram.

Um dos fatores que surpreendeu os pesquisadores desta pesquisa foi a vontade revelada que algumas crianças têm em se tornarem adultos, e interligam o bom de ser criança com um desejo de logo crescerem e exercerem algumas ações que os adultos fazem, e, responderam que é "pra ficar grande, pra ficar rapaz! Pra poder dirigir moto" (Menino 03). Diante dessas narrativas, Passeggi (2014), esclarece que, algumas crianças incorporam o discurso dos adultos. O meio em que as crianças circulam e o contato que elas têm com os adultos pode ocasionar o desejo que elas têm de viverem outras experiências, que muitas vezes não está associado à infância. No entanto, nossa 
perspectiva é a mesma da Sociologia da Infância onde a criança é um ser do presente e não um devir, um ser do futuro, tal como apregoa a sociedade adultocêntrica.

Em suas narrativas, as crianças entendem como é bom ser criança "Pra estudar!" (Menina 01), “pra aprender a ler!” (Menina 02), “pra aprender a escrever, pra fazer o nome" (Menina 03). A partir dessas narrativas, é notório que as crianças produzem a cultura escolar. Na medida em que a escola coloca isso às crianças, ela impõe e sustenta o ofício de aluno, postulado por Sarmento (2011), que predomina sobre a vivência da infância. Ademais, sustenta Sarmento (2011, p. 592) de que: “O ofício de aluno dá lugar a um trabalho escolar da criança sobre si própria, que não mobiliza apenas capacidades cognitivas, mas incide sobre aspectos atitudinais, comportamentais e disposicionais". Sobre isso: "a entrada na escola introduz a criança num novo contexto, planejado pelos adultos com o intuito de prepará-la para assumir, futuramente, um lugar na sociedade" (FURLANETTO, 2014, p. 161).

Ao ser perguntado sobre o que tem de bom em ser criança, uma delas nos responde da seguinte forma "Pra Ficar calado, fazer a tarefa e prestar atenção!” (Menino 06). Essa resposta nos chamou atenção porque revela que na turma do Infantil IV as crianças devem ficar caladas, fazer a tarefa e prestar atenção.

De acordo com o que foi mencionado acima, percebemos que a escola tem por intenção, obter resultados por meio das crianças em testes e em avaliações, tendo como meta principal o rendimento escolar dos alunos a todo custo. É nessa perspectiva que a escola pode ser considerada como um espaço que não leva em consideração a cultura infantil das crianças, pois com a entrada delas na escola, um intenso trabalho se inicia, que objetiva habilitá-las, as tornando, dessa forma, aptas para os processos avaliativos internos e externos. É nesse momento que o sentido de se ter a infância como parte constituinte do processo de formação das crianças é prejudicado.

Desta forma, para Sarmento (2011, p.588): “É o aluno mais do que a criança de quem a escola se ocupa". A escola se ocupa a todo o momento com a preparação e com a formação escolar das crianças, dos materiais, dos conteúdos desta cultura escolar, abandonando, na maioria das vezes, a infância e a criança que existe em cada aluno.

As crianças atribuem o bom de ser criança com as avaliações que fazem na escola. Como é o caso das narrativas sobre avaliação "É bom ser criança pra fazer a avaliação! Pra 
tirar nota boa!" (Menina 04). Ora: “Aprendemos a nos mover nos ritmos impostos pela instituição escolar, a ajustar o nosso tempo nos outros, um tempo coletivo, marcado pelos limites de uma rotina que nasceu de um ritual sagrado" (BUJES, 2006, p. 223). Perdura nas escolas um ciclo vicioso obrigando as crianças a obedecerem a uma rotina repetitiva e massificadora. As crianças não dispõem de uma formação que agregue suas experiências advindas da cultura infantil.

Essa adesão passiva das crianças nos processos avaliativos é compreensível porque: “[...] quanto mais disciplinados, mais flexíveis e mais adaptáveis nos tornamos" (BUJES, 2006, p. 228). Esses fatores refletem muito no tratamento das crianças nas instituições de ensino, que por serem tão disciplinadas, percebem uma liberdade restrita e o sentido de viver a infância na esfera escolar é deixado de lado, uma vez que impulsiona as crianças, desde cedo, a fornecerem resultados. Isso acaba por fazer com que se afastem de sua cultura infantil, pois terão em mente que devem estudar para atender as exigências da escola.

É espantoso ver que crianças do Infantil IV são submetidas a avaliações, visto que algumas diretrizes e regulamentações que regem a educação infantil, como o RCNEl, esclarece que: "Não se trata de avaliar a criança, mas sim as situações de aprendizagem que foram oferecidas. Isso significa dizer que a expectativa em relação à aprendizagem da criança deve estar sempre vinculada às oportunidades e experiências que foram oferecidas a ela" (BRASIL, 1998, p. 65).

O RCNEI é bem claro, enfatiza que na educação infantil o objetivo não é avaliar a criança, e sim às oportunidades e experiências que são ofertadas pelas escolas a elas. A LDBEN, no seu artigo 31, frisa que a avaliação, na educação infantil, deve ocorrer: "[...] mediante acompanhamento e registro do desenvolvimento das crianças, sem o objetivo de promoção, mesmo para o acesso ao ensino fundamental” (BRASIL, 1996, p. 22).

Em nosso diálogo com as crianças, elas também demonstraram algumas situações de lazer que vivenciam com suas famílias e amigos. Elas falaram que é bom ser criança “Porque eu gosto de tomar banho lá no Palmeiras com meus coleguinhas, e também gosto de pula-pula. Gosto de piscina, lá no Palmeiras, com a minha família” (Menino 04).

A partir dessa narrativa, Sartori, Lunardon e Garanhani (2021, p. 12) complementam que: 
[...] vivenciar os espaços, como rua, praia e escola, garantem representações e simbolizações, produzidos por esses espaços na cultura das crianças, distintas para cada uma delas. Além disso, essas representações e simbolizações também se diferem das dos adultos, uma vez que as crianças, através dos espaços, produzem formas específicas de habitá-los.

Atentando a isso, as crianças narram sob diferentes formas e de acordo com seus entendimentos, os espaços que habitam, produzindo narrativas que permitem visitar, simbolizar e identificar esses locais. Palmeiras é o nome de um clube do município da pesquisa onde as famílias vivem momentos de lazer nos finais de semana. Essas narrativas das crianças vislumbram o compartilhamento de vivências com as demais pessoas. Nesse sentido, a experiência humana vincula e agrega aprendizagem da formação humana das crianças de forma individual ou coletiva.

Portanto, retomando as discussões de Sarmento (2011), sobre a reinvenção do ofício de criança e de aluno, é perceptível que as crianças da escola pesquisada se sentem mais alunos do que crianças, o que nos coloca em alerta para uma instituição de ensino que modifica o sentido de viver a infância no espaço escolar, porque as crianças desta pesquisa passam por um processo avaliativo que foge das orientações propostas desde a LDBEN (1996), os RCNEI (1998) assim como pelas DCNEI (2010).

\section{CONSIDERAÇÕES FINAIS}

Esta pesquisa demonstrou como as crianças constroem um campo científico e investigativo de si no momento em que narram suas vivências, além de observar como concebem o fato de ser criança. Verificamos isso nos resultados da pesquisa que apontam três inquietações principais.

$\mathrm{Na}$ primeira inquietação verificamos que as crianças, em suas narrativas, não mencionam o brincar na sala de aula, evidenciando que o saber-conteúdo prevalece nas práticas pedagógicas realizadas na turma do Infantil IV, uma vez que as diretrizes e os parâmetros que regem a Educação Infantil apontam o brincar como parte constituinte da formação das crianças nesse espaço educativo. 
Na segunda inquietação trazemos o desejo de algumas crianças em se tornarem adultos. Isso pode evidenciar que a escola, de fato, ignora a cultura infantil das crianças e elas passam a perder o gosto e a vontade de ser criança, e imaginam que ficar grande e crescer se torna mais divertido à medida que podem realizar atividades prazerosas como, dirigir moto, por exemplo, bem como, as vivências fora da escola no contexto familiar.

A terceira inquietação relata a posição disciplinadora da escola às crianças "Ficar calado, fazer a tarefa e prestar atenção!” (Menino 06). Portanto, questiono se as brincadeiras das crianças não são relevantes em uma instituição de Educação Infantil?

De maneira que esta pesquisa teve grande relevância para a minha formação inicial como pedagogo, já que pude vivenciar no contato com as crianças a minha transição de pesquisador desencantado para uma postura de pesquisador encantado, contribuindo, dessa forma, para a minha futura atuação como pedagogo e professor de crianças, percebendo o ser docente que se constrói pela pesquisa, como postula Freire na obra Pedagogia da Autonomia (1996).

Agora, sinto-me preparado para percorrer outros percursos, pois carrego comigo uma experiência significativa com a certeza de que irei me tornar um educador responsável, comprometido, agente formador e transformador de vidas. Por fim, reitero que sou um ser em constante formação e transformação.

Então, por meio das narrativas das crianças foi possível refletir sobre a infância vivida por elas, deixando evidente a necessidade de uma escuta sensível acerca do processo formativo tanto do pesquisador-iniciante quanto das crianças para que existam possibilidades de transformação, ou seja, de pesquisador desencantado para uma postura de pesquisador encantado. Na esfera educacional as narrativas das crianças podem ser utilizadas para alertarem a respeito da maneira como vivem a infância, de sua formação e de outras questões que vêm à tona quando se realiza uma escuta sensível, como foi feito neste estudo, o qual privilegiou a voz da criança, respeitando o momento e a vontade em querer participar ou não da pesquisa.

\section{REFERÊNCIAS}

BRASIL. Base Nacional Comum Curricular. Brasília, 2018. Disponível em: http://basenacionalcomum.mec.gov.br/ Acesso em: 30. jan. 21. 


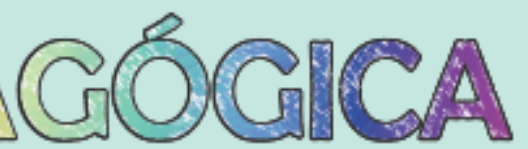

Revista do Programa de Pós-Graduação em Educação da Unochapecó ISSN 1984-1566 (on-line) ISSN 1415-8175 (impressa)

BRASIL. Diretrizes Curriculares Nacionais para a Educação Infantil. Brasília: MEC/SEB, 2010. Disponível em:

http://portal.mec.gov.br/component/content/article?id=12579:educacao-infantil Acesso em: 30. jan. 2021.

BRASIL. Referencial Curricular Nacional para a Educação Infantil. Brasília: SEF, 1998. 3 v. Disponível em: http://portal.mec.gov.br/seb/arquivos/pdf/volume3.pdf Acesso em: 30. jan. 2021.

BRASIL. Resolução n ${ }^{\circ}$ 5, de 17 de dezembro de 2009. Fixa as Diretrizes para a Educação Nacional - DCNEI. Disponível em:

http://portal.mec.gov.br/index.php?option=com_docman\&view=download\&alias=2298rceb005-09\&category_slug=dezembro-2009-pdf\&Itemid=30192 Acesso em: 30. jan.21.

BRASIL. Lei de Diretrizes e Bases da Educação Nacional. Brasília: Senado Federal, Subsecretaria de Edições Técnicas, 1996. Disponível em:

https://www2.senado.leg.br/bdsf/bitstream/handle/id/544283/lei_de_diretrizes_e_bases 2ed.pdf Acesso em: 30. jan. 2021.

BROSTOLIN, M. R; AZEVEDO, A. P. Z. A participação da criança na pesquisa: entre possibilidades e limites. Revista Pedagógica, v. 23, p. 1-19, 2021.

BUJES, Maria Isabel Edelweiss. Outas infâncias?.In: SOMMER, Luís Henrique; BUJES, Maria Isabel Edelweiss (Orgs.). Educação e cultura contemporânea: articulações, provocações e transgressões em novas paisagens. Canoas: ULBRA, 2006.

COHN, Claudia. Antropologia da criança. Rio de Janeiro: Zahar, 2005.

CONTI, Luciane de; PASSEGGI, Maria da Conceição. Reflexões metodológicas sobre a pesquisa com narrativas de crianças. In: MIGNOT, Ana Chrystina; SAMPAIO, Carmen Sanches; PASSEGGI, Maria da Conceição (Orgs.). Infância, aprendizagem e exercício da escrita. Curitiba: CRV, 2014.

COSTA, Antonio Morais da; ASTIGARRAGA, Andrea Abreu. A concepção de ser criança presente nas narrativas do grupo Infantil IV. In: Anais do Fórum Internacional de Pedagogia - FIPED (Edição Salamanca). Anais...Cajazeiras (PB) USAL, 2020. Disponível em: $<$ https//www.even3.com.br/anais/FIPEDSalamanca/280197-A-CONCEPCAO-DE-SERCRIANCA-PRESENTE-NAS-NARRATIVAS-DO-GRUPO-INFANTIL-IV>. Acesso em: 05. mar. 21.

COSTA, Antonio Morais da; ASTIGARRAGA, Andrea Abreu. A narrativa (auto)biográfica de crianças em pesquisas educacionais. In: $V$ Seminário Luso-Brasileiro de Educação Infantil / II Congresso Luso-Afro-Brasileiro de Infâncias e Educação. São Paulo, 2020. Disponível em: <https://www.doity.com.br/anais/clabie2019/trabalho/132020>. Acesso em: 05. mar. 21.

DELORY-MOMBERGUER, Christine. Biografia e educação: figuras do indivíduo-projeto. Natal/RN: EDUFRN; São Paulo: Paulus, 2008. Coleção Pesquisa (Auto)biográfica Educação. 


\section{REVISTA}

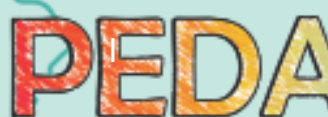

Revista do Programa de Pós-Graduação em Educação da Unochapecó ISSN 1984-1566 (on-line) ISSN 1415-8175 (impressa)

FILHO, Altino José Martins. Jeitos de ser criança: balanço de uma década de pesquisas com crianças apresentadas na Anped. In: FILHO, Altino José Martins; PRADO, Patrícia Dias (Orgs.). Das pesquisas com crianças à complexidade da infância. Campinas, SP: Autores Associados, 2011.

FREIRE, Paulo. Pedagogia da autonomia: saberes necessários à prática educativa. São Paulo: Paz e Terra, 1996.

FURLANETTO, Ecleide Cunico. Contribuições das crianças para (re) pensar as escolas de infância. In: MIGNOT, Ana Chrystina; SAMPAIO, Carmen Sanches; PASSEGGI, Maria da Conceição (Orgs.). Infância, aprendizagem e exercício da escrita. Curitiba: CRV, 2014.

LANI-BAYLE, Martine. A criança e sua história. Por uma clínica narrativa. Trad. Maria da Conceição Passeggi, Sandra Maia Vasconcelos. Natal: EDUFRN, 2018.

LARROSA, Jorge. Notas sobre a experiência e o saber de experiência. Revista Brasileira de Educação, n. 19, p. 20-28, 2002.

LIBÂNEO, José Carlos. Educação: pedagogia e didática - o campo investigativo da pedagogia e da didática no Brasil: esboço histórico e buscas de identidade epistemológica e profissional. In: PIMENTA, Selma Garrido. (Org.). Didática e formação de professores: percursos e perspectivas no Brasil e em Portugal. São Paulo: Cortez, 2011.

LIMA, Maria Emília Caixeta de Castro; GERALDI, Corinta Maria Grisolia; GERALDI, João Wanderley. $O$ trabalho com narrativas na investigação em educação. Educação em Revista. Belo Horizonte, v. 31, n. 01, p.17-44, 2015.

PASSEGGI, Maria da Conceição. Nada para a criança, sem a criança: o reconhecimento de sua palavra para a pesquisa (auto)biográfica. In: MIGNOT, Ana Chrystina; SAMPAIO, Carmen Sanches; PASSEGGI, Maria da Conceição (Orgs.). Infância, aprendizagem e exercício da escrita. Curitiba: CRV, 2014.

ROCHA, Simone Maria da; PASSEGGI, Maria da Conceição. Infâncias e narrativas autobiográficas: cenários, subjetividades e experiências escolares. In: PASSEGGI, Maria da Conceição; DEMARTINI, Zeila de Brito Fabri; NOVAES, Adelina de Oliveira (Orgs.). Infâncias, juventudes, universos (auto)biográficos e narrativas. Curitiba: CRV, 2018.

ROSADO, Cristine Tinoco da Cunha Lima; CAMPELO, Maria Estela Costa Holanda. A voz das crianças sobre sua educação escolar no Rio Grande do Norte. Revista Educação em Questão, n. 24, p. $238-266,2010$.

SARMENTO, Manuel Jacinto. A reinvenção do ofício de criança e de aluno. Atos de pesquisa em educação - FURB, Blumenau, v. 6, n. 3, p. 581-602, 2011.

SARMENTO, Manuel Jacinto. Sociologia da infância: correntes e confluências. In: SARMENTO, Manuel Jacinto; GOUVÊA, Maria Cristina Soares (Orgs.). Estudos da infância: educação e práticas sociais. Petrópolis: Vozes, 2008, p. 17-39. 
SARTORI, E.; LUNARDON, A. M.; GARANHANI, M.C. Espaços, relações e experiências da criança: um estudo sobre crianças de uma geração. Revista Pedagógica, v. 23, p. 1-21, 2021.

SILVA, Alberto Nídio. Brincar e aprender. Aprender a brincar. In: SARMENTO, Teresa; FERREIRA, Fernando Ilídio; MADEIRA, Rosa (Orgs.). Brincar e aprender na infância. Porto Editora, Portugal, 2017.

SOUZA, Solange Jobim e. Linguagem, consciência e ideologia: conversas com Bakhtin e Vygotsky. In: OLIVEIRA, Zilma de Moraes Ramos de (Org.). A criança e seu desenvolvimento: perspectivas para se discutir a educação infantil. São Paulo: Cortez, 2000.

Recebido em: 22 - 04 - 2021

Aprovado em: 07 - 06 - 2021

Publicado em: 28 - 06 - 2021 